\title{
Cuidado em saúde às populaçóes rurais: perspectivas e práticas de agentes comunitários de saúde
}

\author{
I ${ }^{1}$ Amanda Nathale Soares, ${ }^{2}$ Thais Lacerda e Silva, \\ ${ }^{3}$ Adriana Alves de Andrade Melo Franco, ${ }^{4}$ Tatiane Fernandes Maia I
}

Resumo: O objetivo do estudo foi compreender como agentes comunitários de saúde percebem a organização da Atenção Primária à Saúde (APS) para o cuidado à saúde de populaçôes rurais em municípios de pequeno porte do estado de Minas Gerais. Estudo qualitativo, realizado em seis municípios de pequeno porte das regióes Norte e Nordeste de Minas Gerais. Foram realizados seis grupos focais, entre julho e dezembro de 2019. Os resultados evidenciaram diferentes estratégias para ampliar o acesso da população rural a açóes ofertadas na APS, como a construçấo de pontos de apoio e a organização das equipes para ofertarem consultas, visitas domiciliares e determinados procedimentos nos próprios territórios rurais. Entretanto, a organização do cuidado à população rural parece estar mais orientada por critérios clínicos e pela capacidade de deslocamento das equipes e dos usuários do que pelas necessidades de saúde da populaçáo rural. Espera-se que os dados obtidos em diferentes realidades de territórios rurais possam contribuir para o desenvolvimento de estratégias que buscam ampliar e consolidar políticas públicas de saúde para a população rural brasileira.

> Palavras-chave: agente comunitário de saúde; Atenção Primária em Saúde; saúde da população rural.

\author{
'Escola de Saúde Pública \\ do Estado de Minas Gerais. \\ Belo Horizonte-MG, Brasil \\ (amandanathale0708@gmail.com). \\ ORCID: 0000-0003-1341-8142 \\ ${ }^{2}$ Escola de Saúde Pública \\ do Estado de Minas Gerais. \\ Belo Horizonte-MG, Brasil \\ (thaislacerda@gmail.com). \\ ORCID: 0000-0001-9869-9654 \\ ${ }^{3}$ Escola de Saúde Pública \\ do Estado de Minas Gerais. \\ Belo Horizonte-MG, Brasil \\ (adrianafrancoesp@gmail.com). \\ ORCID: 0000-0001-9300-6820 \\ ${ }^{4}$ Escola de Saúde Pública do \\ Estado de Minas Gerais. Belo \\ Horizonte-MG, Brasil (tatiane. \\ maia@esp.mg.gov.br). \\ ORCID: 0000-0002-7541-9901
}

Recebido em: 10/04/2020 Aprovado em: 05/08/2020 Revisado em: 10/09/2020 


\section{Introdução}

A Política Nacional de Atenção Básica (PNAB), instituída em 2006 e reeditada em 2011 e 2017, apresenta diretrizes que orientam a organização da Atenção Primária à Saúde (APS) no país, considerada a porta de entrada prioritária do usuário no Sistema Único de Saúde (SUS) e o lócus privilegiado para o desenvolvimento de cuidado integral à saúde das pessoas. Apesar dos avanços da APS, sobretudo na ampliação da cobertura da Estratégia Saúde da Família e no acesso da população aos serviços de saúde (FACCHINI; TOMASI; DILÉLIO, 2018), permanece o desafio de garantir o direito e o acesso à saúde da população rural.

Estudos apontam que, quando comparada à população urbana, a situação de saúde da população rural é mais precária, com baixa cobertura de saneamento básico $(32,8 \%)$ e maior parte da população $(67,2 \%)$ captando água sem tratamento ou com condições insalubres, o que impacta no número de doenças de veiculação hídrica, parasitoses intestinais e diarreias (BRASIL, 2014). Os moradores de comunidades rurais avaliam pior sua própria saúde quando comparados à população urbana, mas procuram menos pelo serviço de saúde. Isso pode estar relacionado a uma menor oferta de serviços nas proximidades rurais, exigindo dos usuários gastos financeiros para deslocamentos (ARRUDA; MAIA; ALVES, 2018). Realidade semelhante é observada em outros países, como Estados Unidos, no qual o acesso a determinados procedimentos de saúde pela população rural é restrito (BHAT et al., 2020).

Visando à diminuição das iniquidades em saúde relacionadas à população rural, foi publicada, em 2014, a Política Nacional de Saúde Integral das Populaçóes do Campo e da Floresta (PNSIPCF), considerada um avanço para a garantia do direito e do acesso à saúde no SUS. A ampliação da APS como estratégia para a garantia do acesso da população a serviços de qualidade, com equidade e em tempo adequado ao atendimento das necessidades de saúde, é um dos eixos do Plano Operativo da PNSIPCF (BRASIL, 2014).

No âmbito da APS, sobretudo em áreas rurais, o agente comunitário de saúde (ACS) é o trabalhador que reduz a distância entre a população e o serviço de saúde, identificando e reconhecendo as necessidades de saúde da população e ampliando a compreensão da comunidade sobre modos de produzir o cuidado e formas de acessar os serviços de saúde. Estudo realizado na África do Sul aponta que ACS de áreas rurais buscam suprir lacunas relacionadas às políticas públicas, inclusive 
disponibilizando recursos financeiros próprios para alimentação e transporte dos usuários nos dias de consultas e tratamentos (SIPS et al., 2014).

Com base no exposto e reconhecendo a centralidade da atuação do ACS nas áreas rurais, este estudo intenta compreender como ACS percebem a organização da APS para o cuidado à saúde de populaçóes rurais em municípios de pequeno porte do estado de Minas Gerais. Espera-se que os dados obtidos em diferentes realidades de territórios rurais possam contribuir para o desenvolvimento de estratégias que buscam ampliar e consolidar políticas públicas de saúde para a população rural brasileira.

\section{Metodologia}

Pesquisa qualitativa de caráter descritivo e exploratório, realizada com ACS de seis municípios das regiōes Norte e Nordeste de Minas Gerais, locais onde a Escola de Saúde Pública do Estado de Minas Gerais (ESP-MG) ofertou o Curso de Qualificação de ACS, no segundo semestre de 2019. Considerando a importância de representar diferentes características territoriais, selecionou-se aleatoriamente um munícipio das cinco regionais de saúde em que o curso foi realizado. Uma das regionais de saúde foi contemplada por dois municípios dada a proximidade entre eles.

De acordo com informaçôes do Censo Demográfico 2010, os seis municípios são de pequeno porte, com população entre 3.966 e 24.912 habitantes. Um dos municípios possui quase $65 \%$ da população em área rural; outros quatro possuem entre $35 \%$ e $40 \%$ de população rural; e um possui $23 \%$. Quase a totalidade da população dos municípios é SUS-dependente, sendo o menor percentual 97,46\% e o maior 99,59\%. Dos 136 ACS que atuam nesses municípios e realizaram o Curso de Qualificação de ACS, 43\% atuam na área rural, sendo 80\% o maior percentual e $24 \%$ o menor. Em relação ao percentual da população em extrema pobreza, varia de 13,85\% a 32,37\% (IBGE, 2011). Esses dados demonstram a importância da APS, que é, muitas vezes, a expressão mais concreta de proteção social à população que vive nesses municípios.

Foram realizados seis grupos focais, com participação de 7 a 15 ACS em cada, entre julho e dezembro de 2019, considerando as seguintes questôes: conte um pouco sobre a experiência de vocês como ACS da zona rural. Como você e sua equipe se organizam para oferecer o cuidado à população rural? Os critérios de inclusão para participação foram: estar matriculado no Curso de Qualificação de 
ACS, atuar em áreas rurais e aceitar participar da pesquisa. Os critérios de exclusão foram: atuar exclusivamente em área urbana e não desejar participar da pesquisa. Foram convidados todos os ACS matriculados no Curso de Qualificação de ACS da ESP-MG que atuavam na área rural. Todos aceitaram o convite e participaram do grupo focal. Os grupos, realizados em dependências de escolas públicas ou de Unidades Básicas de Saúde (UBS), duraram em média 90 minutos.

A opção pela técnica do grupo focal, baseada em Dall'Agnol e Trench (1999), decorreu da necessidade de ampliar a compreensão sobre a organização da APS para o cuidado à saúde da população rural a partir de pontos de vista de ACS inseridos em diferentes municípios que possuem uma proporção importante da população vivendo em áreas rurais. A vantagem de se utilizar o grupo focal está na possibilidade de intensificar o acesso às informaçóes acerca de um fenômeno vinculado ao cotidiano de trabalho, por meio de uma interação grupal caracterizada pelo debate de opiniōes e experiências em torno de um objeto comum (LOPES et al., 2010).

O material gravado e transcrito foi submetido à análise de conteúdo, seguindo as fases de pré-análise, exploração do material e tratamento dos resultados (BARDIN, 2016). As categorias foram definidas a posteriori, dado o caráter exploratório da pesquisa, considerando tendências, convergências e divergências que emergiram do material. A pesquisa foi aprovada pelo Comitê de Ética em Pesquisa (Parecer CEP 2.429.103). Os participantes estáo identificados pela sigla ACS e os grupos focais pela sigla GF, seguidos dos números que os designam.

\section{Resultados e Discussão}

A partir da análise dos grupos focais, foram definidas três categorias temáticas: (i) estrutura e funcionamento de unidades de apoio nas zonas rurais; (ii) organização das equipes para atendimento individual e coletivo à população rural; e (iii) acesso a serviços e açóes centralizados nas zonas urbanas.

\section{Estrutura e funcionamento de unidades de apoio nas zonas rurais}

Esta categoria aborda como os ACS percebem a estrutura e o funcionamento dos pontos de apoio construídos nas áreas rurais como estratégia para atender às necessidades de saúde da população rural. Os pontos de apoio são espaços físicos vinculados às UBS e destinados ao atendimento de populaçôes dispersas, com 
reconhecimento no Sistema de Cadastro Nacional de Estabelecimentos de Saúde (SCNES) (BRASIL, 2017).

É unânime entre os ACS participantes deste estudo a necessidade dos pontos de apoio, também chamados de "postinhos", para favorecer o acesso da população rural ao cuidado em saúde, considerando as extensas distâncias entre as moradias e a UBS localizada na cidade.

Nosso PSF tem a sede e mais 4 postinhos pra poder ficar mais próximo das comunidades. $\mathrm{Na}$ comunidade onde atuo, tem o postinho que atende aquela região próxima ali. Porque se for pra sede, fica longe demais... não tem como... a zona rural é muito extensa. É uma casa aqui, daqui $10 \mathrm{~km}$ tem mais uma, daqui $15 \mathrm{~km}$ mais uma casa... (ACS1, GF1).

Na microárea que atendo tem dois pontos de apoio, porque a distância pra população ir até a unidade é extensa, uns $30 \mathrm{~km}$. (ACS2, GF2).

Essas falas revelam o desafio imposto à gestão municipal e às equipes de APS para organizar o acesso das populaçóes rurais ao cuidado em saúde, reafirmando a importância da construção de pontos de apoio mais próximos às comunidades rurais, sobretudo em municípios com grande percentual de população rural e/ou com populaçóes que vivem dispersamente em amplas extensôes territoriais rurais, como os que participaram deste estudo. A superação da distância entre as moradias rurais e as equipes de saúde da família é um grande desafio para a garantia da atenção à saúde às populaçôes rurais (PESSOA; ALMEIRA; CARNEIRO, 2018).

Embora seja unânime entre os ACS a importância dos pontos de apoio para ampliação do acesso à saúde da população rural, a sua construção requer apoio e decisão da gestấo municipal. Em um dos municípios, a discussão e a mobilização do gestor municipal para a construção dos pontos de apoio foram iniciativas dos próprios ACS que atuam nas áreas rurais.

Foi feito e está sendo providenciado outros pontos de apoio na zona rural porque a gente tinha dificuldade [...] houve várias reuniōes, a pressão dos ACS até que a administração entendeu que precisava de pontos de apoio em cada comunidade... ainda não são em todas, mas tá sendo providenciada... na minha microárea atendo três comunidades, duas já foram beneficiadas com ponto de apoio... (ACS3; GF3).

A fala acima revela uma dimensão importante do papel do ACS, que é a contribuição para a garantia do direito à saúde. Sobre isso, destaca-se que o ACS, sobretudo em sua atuação nas zonas rurais, constitui uma personificação do acesso à saúde para a comunidade, seja sendo uma referência primeira, e às vezes única, para 
acolher as demandas da população (LACERDA et al., 2020), seja identificando e construindo orientaçóes e encaminhamentos às necessidades de saúde das pessoas, seja buscando articulaçóes junto a diferentes atores para o desenvolvimento de melhorias no sistema de saúde local (PINTO et al., 2017).

Nessa direção, o ACS é essencial para viabilizar apoio, implementação e desenvolvimento de açóes voltadas para a comunidade, contribuindo para expandilas e fortalecê-las na realidade local (SANTOS; PIERANTONI; SILVA, 2010). Embora os ACS, em geral, não se sintam apoiados e reconhecidos pela gestão (ALONSO; BÉGUIN; DUARTE, 2018), no município acima é importante destacar que é exatamente pela relação construída entre ACS e gestão municipal que se tornou possível a construção de pontos de apoio para ampliar o acesso à saúde para as comunidades rurais.

Nesse mesmo município, um ACS colocou que a estrutura que vem sendo construída para os pontos de apoio atende às necessidades da equipe e da populaçáo, que passam a ter um espaço apropriado para acolhimento e compartilhamento de suas questôes de saúde.

Antes paciente era atendido no quarto da casa de um usuário... a privacidade era pouca, muitas vezes o calor é muito e tem que ficar com janela aberta, o pessoal fica tendo acesso à escuta e à visão mesmo... então tinha esse receio do paciente tá se abrindo com o médico... hoje melhorou bastante, porque a gente conta com esse ponto de apoio... tem dois banheiros, uma sala pro médico atender, uma sala pro dentista, um espaço coberto com ventilador pro pessoal ficar...(ACS3; GF3).

Embora os pontos de apoio sejam reconhecidos como espaços que devem respeitar as normas gerais de segurança sanitária (BRASIL, 2017), observa-se uma heterogeneidade na sua estrutura entre os diferentes municípios. Revela-se que, em alguns municípios, sua estrutura não é adequada às necessidades de atendimento.

[...] esses postinhos, geralmente, são duas ou três salinhas, um banheiro. Não é uma estrutura bacana [...] (ACS4; GF1).

[...] nos pontos de apoio náo tem maca. Pra fazer o preventivo nós pegamos a maca aqui e levamos, arrumamos uma casa de um morador, ele cede o espaço pra gente. É feito na casa de um morador. (ACS2, GF2).

A segunda fala aponta que, embora o município disponha de ponto de apoio, a sua estrutura é insuficiente para o atendimento, cabendo ao ACS, por exemplo, o deslocamento de uma maca e a identificaçáo da casa de um morador para a realização do exame preventivo de câncer de colo do útero. Acresce-se a isso o fato 
de que, em outro município, também fica sob responsabilidade do ACS a limpeza do ponto de apoio.

Além de todas as dificuldades que a gente tem, a limpeza do posto também é nós que fazemos. [...] Tem preventivo? Você vai ter que ir lá limpar o postinho. Vai ter a reunião? Tem que ir lá. Vai ter consulta? Tem que limpar. [...] lavar também os lençóis da cama... camisolas... [...] na sede tem uma faxineira, mas quem tem os postinhos, tipo eu, tem que limpar. (ACS5; GF1)

Essa fala coloca em evidência a multiplicidade de atribuiçóes que o ACS acumula para que a população rural seja atendida no território em que vive. Conforme apontado em alguns estudos, a falta de dimensionamento do trabalho do ACS é uma questão que merece ser discutida, pela pouca clareza de suas atribuições, pelo excesso de funçóes previstas (ALONSO, BÉGUIN, DUARTE, 2018) e/ou pela realizaçáo de tarefas que não lhe competem (MOROSINI; FONSECA, 2018).

Ainda sobre a estrutura para atendimento às populaçôes rurais, observa-se que, em alguns municípios, são utilizados os espaços de alguns dispositivos comunitários, como igreja e escola.

Na minha comunidade o atendimento é na escola. Lá tem uma maca só e sem estrutura.

É um espaço físico só. (ACS6; GF4).

Nas outras comunidades, só tem a igreja e os atendimentos médicos são lá na igreja. (ACS7; GF1)

É importante destacar a especificidade que o cuidado em saúde às populações rurais adquire quando é realizado no próprio território rural. Os espaços comunitários, por vezes, se confundem com os locais para atendimento em saúde, o que, por um lado, favorece o acesso à saúde nas comunidades rurais, mas, por outro, revela a precariedade com que, muitas vezes, são tratadas as necessidades de saúde da população rural. Essa realidade revela que, em muitos municípios, são utilizados "pontos de apoio" improvisados que não constam no SCNES, o que contribui para manter invisível a demanda das populaçôes rurais e a atuação de equipes de APS sem estrutura física adequada (PESSOA; ALMEIRA; CARNEIRO, 2018).

Além da heterogeneidade da estrutura dos pontos de apoio observada nos diferentes municípios, observam-se arranjos distintos de funcionamento. Há municípios cujos pontos de apoio são destinados apenas aos atendimentos mensais.

Lá é só para atendimento mensal. O dia que o médico for, aí o postinho tá em funcionamento. Não tem aquelas 8 horas de funcionamento. É uma vez por mês... (ACS7; GF1). 
Lá no meu postinho, uma vez por mês o médico e a técnica de enfermagem vão. (ACS2; GF2).

Essas falas parecem revelar uma subutilização da estrutura dos pontos de apoio que permanecem em funcionamento apenas um dia por mês. Diferentemente, em outros municípios, nos pontos de apoio há uma presença maior dos profissionais de saúde, inclusive com a atuação diária de um técnico de enfermagem.

Lá no meu ponto de apoio a técnica de enfermagem está todos os dias. O que diferencia é o médico e o dentista, que vão 3 vezes no mês. (ACS8; GF2).

Em um dos locais, o serviço funciona de 7 às $11 \mathrm{~h}$ e de $13 \mathrm{~h}$ às $17 \mathrm{~h}$. O médico, o enfermeiro, o fisioterapeuta e o dentista vão uma vez por semana, de $7 \mathrm{~h}$ às $11 \mathrm{~h}$. Nesse horário fica uma técnica de enfermagem, a gente e uma recepcionista. Quem fica lá no posto todos os dias da semana de $7 \mathrm{~h}$ às $11 \mathrm{~h}$ e de $13 \mathrm{~h}$ às $17 \mathrm{~h}$ é só a técnica de enfermagem. (ACS9; GF5).

Sobre a presença do técnico de enfermagem nos pontos de apoio, uma ACS destacou a importância desse profissional para realizar o acompanhamento dos usuários.

$\mathrm{Na}$ minha área tem mais hipertenso... então disponibilizaram pra lá um técnico de enfermagem... todo dia... é muito bom... porque minha área é a mais distante... e quando a pessoa precisa fazer um acompanhamento de pressão cinco dias seguidos, ela vai lá todo dia... então com essa disponibilidade do técnico de enfermagem, fica bem mais acessível...(ACS10; GF3).

Além disso, a atuação do técnico de enfermagem no ponto de apoio atende também à demanda da população rural relacionada à coleta de materiais para exames laboratoriais.

Uma coisa que eu tô achando legal que tá acontecendo agora é a coleta de laboratório... pra não precisar o pessoal se deslocar pra cá pra fazer a coleta de laboratório, sangue, fezes, essas coisas... ai o técnico tá indo fazer a coleta... (ACS11; GF3).

Essas falas demonstram que a presença do técnico de enfermagem nos pontos de apoio torna-se essencial para a população rural acessar procedimentos como aferição de pressão arterial e coleta de materiais para exames laboratoriais. A possibilidade de ter um técnico de enfermagem mais próximo às comunidades rurais é uma demanda reconhecida pelos ACS e vai na contramão da proposta da PNAB 2017 de incorporar procedimentos dessa natureza ao escopo de atribuiçóes do ACS. Embora a PNAB 2017 incorpore novas atribuiçōes aos ACS sob a prerrogativa de ampliar o cuidado à saúde da populaçáo, contraditoriamente, faculta ao gestor municipal a composição de equipes de Atenção Básica (eAB) sem a presença de ACS e de equipes 
de Saúde da Família com apenas um ACS. Essa possibilidade fragiliza ainda mais o acesso de populaçóes rurais aos serviços, na medida em que o ACS é o principal elo entre a comunidade e as equipes de saúde (LACERDA et al., 2020; BRASIL, 2017).

Outra questão que surgiu em relação à necessidade de ampliação do acesso à saúde da população rural refere-se aos horários de funcionamento dos pontos de apoio. Sobre isso, uma ACS destacou que sua equipe está discutindo a proposta de rever o horário de funcionamento, considerando as especificidades do trabalhador rural.

A gente ta com uma proposta... já tinha conversado com a médica, de trabalhar a questáo
do horário... a gente tava comentando que ta achando bacana atender pessoal mais à
noite... o trabalhador rural, por exemplo, ele trabalha das 5 da manhã e só chega à noite,
6 horas da tarde... a gente ta tentando bolar alguma coisa pra um dia ter atendimento
específico fora do horário... no ponto de apoio... (ACS12; GF3).

Essa fala ressalta a necessidade de adequaçáo do funcionamento dos pontos de apoio à realidade de vida das comunidades rurais, conforme também aponta estudo realizado na Regiáo Norte do país, que constatou que os usuários de zonas rurais enfrentam importantes problemas de acesso devido ao horário de funcionamento das unidades (GARNELO et al., 2018).

\section{Organização das equipes para atendimento individual e coletivo à população rural}

Esta categoria aborda as compreensôes dos ACS sobre como as equipes de Saúde da Família e o Núcleo Ampliado de Saúde da Família e Atenção Básica (NASF-AB) têm se organizado para realizarem atendimento individual e coletivo às populaçóes rurais nos pontos de apoio, nas visitas domiciliares e nos grupos de saúde.

Em relação aos atendimentos médicos, observa-se que, embora estejam concentrados nos pontos de apoio, também são realizados nas visitas domiciliares, quando necessário.

Na minha área, sempre que tem necessidade a médica vai fazer o atendimento em casa... independente do dia que já vai mensalmente no ponto de apoio... precisou, tem o atendimento em casa...(ACS10; GF3).

A fala do ACS expressa a capacidade de os profissionais da UBS garantirem à população rural o acesso às consultas médicas, seja no ponto de apoio, seja no atendimento às demandas por visitas domiciliares. Esse achado diverge da realidade da maior parte dos serviços de APS que atendem à população rural, os quais 
encontram inúmeras dificuldades para viabilizar visitas domiciliares (SILVA, 2017). Embora a visita domiciliar seja reconhecida como uma ferramenta essencial para o atendimento individual, na medida em que possibilita ao profissional um olhar ampliado sobre o meio onde o usuário vive, nas áreas rurais sua viabilização requer a disponibilização de veículo próprio da UBS/secretaria de saúde, o que, na maioria das vezes, não ocorre.

No estudo de Silva (2017), denota-se que a organização das visitas domiciliares à população rural é orientada por critérios clínicos e pelo quantitativo de pessoas nas comunidades rurais. Diante das grandes extensóes territoriais rurais e da relativa dispersão populacional, observa-se, muitas vezes, a priorização de visitas em áreas com maior concentração de pessoas. Em outro estudo, os dados do Programa Nacional de Melhoria do Acesso e da Qualidade da Atenção Básica dos sete estados da Região Norte do Brasil evidenciaram que um terço das equipes de saúde não dispóe de transporte para realização de suas atividades, restringindo, assim, a oferta de visitas domiciliares (GARNELO et al., 2018).

Ainda sobre o atendimento médico, outros ACS colocaram as dificuldades para contemplar as demandas dos territórios rurais, seja pela dificuldade de fixação do médico na zona rural, seja em decorrência do número insuficiente de atendimentos ofertado.

Por ser zona rural, não se encontra médico fácil. E quando encontra, ele tem suas imposiçóes. Antigamente, a gente tinha médico que fazia visita domiciliar, atendia a quantidade de pacientes que chegavam no dia, passava do horário.... Hoje em dia, se o médico passa do horário, tira essas horas convertidas em folgas. Isso está nos dificultando muito. (ACS1; GF1).

Na minha área tem um assentamento. São umas 50 famílias. O médico vai lá e é assim: se tiver 28 pessoas ele não atende. É porque na realidade acho que esse programa "Mais Médicos" tem uma quantidade. Tinha que ir mais vezes, de $15 \mathrm{em} \mathrm{15.} \mathrm{Em} \mathrm{uma} \mathrm{quinzena}$ atende 15 e outra quinzena atende mais 15 . Aí o povo desloca de tão longe e não é atendido, e aí? (ACS13; GF4).

A primeira fala destaca a dificuldade de provimento e de fixação de médicos, o que se desdobra, entre outras questóes, nas dificuldades para atender às demandas e às especificidades da populaçáo rural. Embora no país diferentes estratégias tenham sido adotadas para provimento, fixação e reformulação da força de trabalho médica para atuação na APS, as regiôes mais carentes e/ou remotas, como os municípios em que este estudo foi desenvolvido, ainda apresentam maiores dificuldades de 
atrair e fixar esses profissionais (STRALEN et al., 2017). Para além das dificuldades relacionadas à fixação de médicos nas equipes da APS, mesmo quando há o profissional na equipe, observa-se que o acesso da população rural às consultas ainda é restrito. Isso pôde ser observado no segundo trecho, o qual revela que o deslocamento do médico à regiáo de assentamento uma vez por mês não atende às necessidades das famílias, o que exigiria a reorganização da agenda médica, com ampliação do tempo dedicado às consultas no assentamento.

Em relação ao atendimento individual de outros profissionais, como enfermeira e dentista, observa-se que, em alguns municípios, também é realizado periodicamente, nos pontos de apoio e nas visitas domiciliares.

$\mathrm{Na}$ comunidade deles tem bastante criança, aí é difícil pras mães virem com a criança fazer o acompanhamento... aí a enfermeira se desloca pra lá uma vez por mês pra fazer o cartáo de vacina pra náo precisar vir todo mês... por isso o ponto de apoio... a equipe tá se disponibilizando a sair daqui e ir pra lá melhorou muito... (ACS3; GF3).

Tem alguns curativos também que é em pessoas especiais... levam os materiais e fazem na casa... Vai o enfermeiro ou técnico, não precisa da pessoa se deslocar pra cá... (ACS14; GF6).

$\mathrm{O}$ atendimento com o dentista a gente divide... eu, por exemplo, vou ter 3 dias por mês pra fazer meu agendamento, cada um desses dias eu tenho 6 vagas pra atendimento odontológico... (ACS15; GF6).

É importante observar que muitos dos esforços empreendidos para a organização do cuidado à população rural possuem centralidade na ampliação do acesso às consultas e a determinados procedimentos assistenciais, a exemplo dos curativos. Embora o acesso a esses serviços seja fundamental, esse enfoque expressa marcas de um modelo de cuidado biologicista, centrado em ações de atendimento individual e curativo. Conforme apontam Costa et al. (2019), o cuidado à saúde em territórios rurais requer da equipe o conhecimento sobre as necessidades e as especificidades relacionadas aos modos de vida e trabalho dessas pessoas; do contrário, a equipe atuará na reproduçáo do modelo urbano.

Em relação ao atendimento de profissionais que integram o NASF-AB, há relatos de ACS que, por um lado, mostram a presença desses profissionais no atendimento à população rural, ainda que insuficiente para atender às demandas e, por outro, revelam a dificuldade de o NASF-AB chegar às comunidades rurais.

A questão da visita do NASF, eles vão. A assistente social e a psicóloga. A gente tem uma demanda, se organiza quando ela vai uma vez, duas vezes no máximo, no 
mês. A gente junta a equipe, vê os casos mais urgentes e agenda pra ela visitá-las. [...] só que é delicado porque é uma demanda grande... Mas, sempre que podem, a gente divide os casos mais delicados e faz as visitas. No início do ano, a gente teve muita dificuldade devido a transporte. $\mathrm{O}$ psicólogo, o assistente social, nutricionista, não têm como ir no carro que vai levar o médico porque não tem disponibilidade de horário nem vaga. [...] Mas a dificuldade é grande porque nós já não temos muitos dias disponíveis e, quando tem, acontece de não ter o carro pra levar. (ACS16; GF1).

Os relatos dos ACS expressam, mais uma vez, que a disponibilidade de veículo e os critérios clínicos são fatores determinantes para a organização das visitas domiciliares em territórios rurais. Na primeira fala, fica evidente que a demanda relacionada à saúde mental é grande; no entanto, a psicóloga se organiza para fazer a visita uma vez por mês, dando prioridade para alguns casos considerando o ponto de vista clínico. $\mathrm{Na}$ segunda fala, observa-se que, mesmo os profissionais do NASF tendo agenda disponível para as visitas domiciliares nas áreas rurais, elas são limitadas, pela falta do carro ou pela concorrência do uso do carro pelo médico.

Nas situaçôes em que há alguma demanda de urgência e não há a possibilidade de o usuário da zona rural se deslocar até a UBS da cidade, os municípios organizam distintas estratégias de deslocamento para o atendimento. No mesmo município, em uma microárea há o deslocamento dos profissionais de saúde até a área rural; em outra, providencia-se o deslocamento do usuário até a UBS da cidade.

O médico atendeu hoje, alguém amanhã passou mal, liga na unidade, manda um carro lá na zona rural, busca, faz o atendimento, manda de volta para casa. (ACS17; GF6).

Alguém tá passando mal, a gente vem, aciona a enfermeira, ela vai com o médico lá, vê esses pacientes que têm dificuldades de vir até a unidade. [...] (ACS15; GF6).

A segunda fala coloca em evidência o papel do ACS em situaçóes de urgência nas zonas rurais. É o ACS que vai até o usuário que está se sentindo mal e contacta a enfermeira para solicitar atendimento domiciliar. Se a organização de pontos de apoio e a disponibilização de equipes nas áreas rurais para o acompanhamento longitudinal da situação de saúde é um grande desafio para a gestão municipal, isso se torna ainda mais complexo no atendimento às urgências em territórios rurais, especialmente quando se consideram as características dos municípios deste estudo. Nota-se que o ACS exerce papel de referência para situaçôes de urgência e conta com o apoio da enfermeira da UBS para realizar os encaminhamentos. 
As falas de outras ACS reforçam a centralidade que o agente ocupa na vida das pessoas que moram em áreas rurais, o qual se constitui a única referência para o cuidado em saúde.

Eu já cheguei em casa na zona rural que a pessoa estava esperando eu ir lá pra começar a tomar o remédio, porque ela não sabia tomar. $\mathrm{Na}$ zona urbana, mesmo se a pessoa não sabe, ela pede um vizinho, vai no posto. Na zona rural isso não acontece." (ACS18; GF2).

Normalmente, na zona urbana, quem precisa vai na UBS e resolve. Na zona rural tudo é com a gente, primeiramente. Você chega lá, o idoso é sozinho, tá carente, você conversa, organiza um exame. Ele considera a gente da família. (ACS 19; GF2).

A segunda fala imprime um sentido adicional à presença do ACS, que, pela proximidade e pelo vínculo, torna-se parte da família. No meio rural, a família, e aqui se pode incluir o ACS, representa um fator de proteção para o envelhecimento, a principal fonte de recurso e apoio, uma vez que os recursos sociais de saúde são escassos ou inexistentes (BERTUZZI; PASKULIN; MORAIS, 2012).

Quanto às atividades voltadas para determinados grupos/coletividades, os ACS referiram o desenvolvimento de grupos de saúde, realizados predominantemente na UBS da cidade, o que limita a participação de usuários da área rural.

Além das visitas, a gente faz palestras sobre tabagismo, Hiperdia nas comunidades, reuniẫo sobre saúde da mulher... tem esses trabalhos que a gente vem fazendo de incentivo... (ACS15; GF6).

No ponto de apoio não tem grupos... Os usuários têm que ir pra UBS, mas os da roça não văo. (ACS8; GF2).

Em um dos municípios, a equipe organizou um grupo na área rural, com encontros mensais, sendo considerado um sucesso.

Lá tem quarenta e tantos hipertensos... eu fui, levei a enfermeira, tinha os grupos aqui na cidade, eles não podiam vir... a gente chegou, montou o grupo, tem todo mês, todo mundo vai... já tem a cobrança... e aí, vai ter o grupo não?! (ACS3; GF3).

Embora esse município demonstre uma experiência interessante de realização de grupo na comunidade rural, o que se observa, em geral, é a organização da equipe para ampliar o acesso de usuários das áreas rurais a consultas e visitas domiciliares, seguindo critérios clínicos para priorização. Esses achados apontam a necessidade de a organização do cuidado às populaçôes rurais considerar, para além do acesso a atendimentos individuais, modos de cuidado que reconheçam e atendam, mais amplamente, às necessidades de saúde das pessoas que moram nesses territórios. 


\section{Acesso a serviços e açóes centralizados nas zonas urbanas pela população rural}

Esta categoria aborda as percepçóes dos ACS sobre as dificuldades da população rural para acessar serviços e ações que estão concentrados nas áreas urbanas, considerando as questôes de deslocamento e os processos de organização do serviço. Para além do atendimento que é ofertado pelas equipes nos pontos de apoio, nas visitas domiciliares e nos grupos de saúde, observam-se as restriçôes de acesso da população rural, por exemplo, a exames, fisioterapia e consultas especializadas, que estão centralizados nas regióes urbanas.

Em relação ao acesso a exames, os ACS destacaram a dificuldade de deslocamentos da população rural, pelas condiçóes do transporte escolar utilizado, pela ausência de meio de transporte ou, ainda, pelos altos valores que gastariam para se deslocarem.

Para os pacientes de zona rural, sempre a dificuldade é a realização dos exames que são marcados na cidade porque às vezes nem transporte tem... a linha de ônibus passa só alguns dias e tem um horário pra fazer esses exames. [...] minha área não tem nem rota de carro pra vim, é preciso frete. Uma passagem custa 25,00 a 30,00 reais. Eles têm que ir uns 8 ou $9 \mathrm{~km}$ pra conseguir transporte. [...] aí, cê imagina uma máe que tá com exame marcado pra três crianças que também pagam passagem... Uma família que só vive da roça... às vezes, do Bolsa Família. Ela vai ter condiçấo de pagar? Tem gente que fala: "ah, não vou consultar porque sei que o médico vai pedir exame e não tenho como fazer" [...] (ACS5; GF1).

O pessoal da zona rural tem dificuldade de vir aqui... [...] muitas vezes eles usam o transporte escolar, mas reclamam que o ônibus tá cheio, que tem muito usuário... mas é o transporte que eles têm... (ACS3; GF3).

As falas demonstram que a população rural assume o ônus físico e financeiro do deslocamento até a cidade para realizar exames, o que significa novas barreiras de acesso ao cuidado. Essas dificuldades de deslocamento revelam que, embora os pontos de apoio facilitem o acesso à saúde, a continuidade do cuidado permanece pouco acessível. Quando se pensa em acesso à saúde no SUS, há que se destacar a profundidade da questão que se impóe às comunidades rurais. Isso porque as iniquidades não decorrem apenas das distâncias geográficas, mas envolvem aspectos mais amplos de determinaçáo social, como desigualdades de poder aquisitivo e de posse de meios de transporte, que se sobrepóem às barreiras de acesso aos serviços de saúde (GARNELO et al., 2018).

Além disso, os ACS também destacaram que o modo como está organizado o serviço restringe o acesso da população rural à realização dos exames. 
Outra coisa que fica difícil é os exames; pelo fato de ser zona rural, eles tinham que dar um prazo, determinar assim: essa semana é zona rural. As famílias que a gente lida são muito carentes. Aí, eu ligo avisando que saiu o exame. Se aquela pessoa fala que não pode ir, ela volta lá pro final da lista e isso não é justo. A gente que está lá sabe a condição financeira que ela tem. (ACS18; GF2).

É importante destacar como os ACS, conhecendo a realidade da populaçáo rural, atentam para as possibilidades de flexibilização da organização e dos fluxos de trabalho dos serviços de saúde para ampliar o acesso das comunidades rurais aos exames centralizados na cidade. Apesar das já conhecidas dificuldades que as populaçôes rurais enfrentam para acessar os serviços, parece ser também necessário que as equipes de saúde se sensibilizem com as necessidades do usuário rural e atenuem a rigidez de suas programaçóes e de seus funcionamentos para melhor atender aos que vêm de longe (GARNELO et al., 2018).

Os ACS apontaram também as dificuldades de acesso a consultas especializadas e atendimentos fisioterápicos decorrentes da falta de transporte, enfatizando suas implicaçóes nas condiçôes de saúde e doença da população rural.

Para minha comunidade vir pra Policlínica, a passagem é 25,00 reais. São $18 \mathrm{~km}$ de distância. Então, às vezes, as pessoas acabam desistindo porque não têm dinheiro... O carro só faz a linha em dois dias na semana. É muito dificultoso. Às vezes, as pessoas acabam desistindo por isso e ficam sem tratamento. (ACS7; GF1).

Às vezes, tem paciente da zona rural que sofre algum tipo de acidente e que precisa fazer fisioterapia. Tem que vir pra cidade pra ser cuidado. [...] (ACS20; GF1).

Essa situação aponta que é a disponibilidade de recursos para o deslocamento que define o tipo de serviço a que as populaçôes rurais terão acesso, que, em geral, se limita às ofertas da APS que estão localizadas mais próximas às comunidades rurais. Embora o direito à saúde envolva o acesso a todo e qualquer serviço que se faça necessário para o cuidado, denota-se que o acesso à saúde pela população rural não é definido pelas necessidades das pessoas, mas pela possibilidade que têm para se deslocar. Discutir o direito à saúde das populaçóes rurais exige, necessariamente, mapear as (im)possibilidades de deslocamento entre seus territórios e a cidade, identificando as especificidades que cada comunidade possui.

Compreendendo essa realidade, alguns ACS destacaram as estratégias que realizam para tentar melhorar o acesso da população rural, fazendo adaptaçôes no transporte, organizando a marcação das consultas ou, ainda, mobilizando outras pessoas para ajudar no deslocamento até a cidade. 
O pessoal da zona rural usar o transporte escolar é um desgaste... o ônibus escolar é muito alto... a maioria das senhoras idosas não consegue entrar... então eu tive que providenciar uma escadinha pra elas subirem... [...] (ACS3; GF3).

Pro pessoal da minha microárea ir na unidade consultar só tem um ônibus. Vai 7 horas e volta 3 da tarde e náo tem como ficarem lá esperando o ônibus pra voltar. $\mathrm{O}$ motoqueiro cobra 15 reais pra buscar na UBS. Tem hora que fico dando ajeito. Eu marco consulta pra 4 pessoas porque sei que um vai de carro e pode dar carona pros outros. (ACS 21; GF2).

Essas falas destacam como o ACS que atua em áreas rurais busca soluções, por vezes paliativas, para ampliar o acesso da população aos serviços de saúde localizados na cidade. Como o ACS se vincula estreitamente às realidades das famílias e se implica com as dificuldades que vivenciam, ele produz movimentos de invençâo capazes de dinamizar as lógicas de funcionamento do transporte e da UBS e potencializar o atendimento às necessidades da comunidade (BAPTISTINI; FIGUEIREDO, 2014).

\section{Considerações finais}

Os resultados desta pesquisa evidenciam modos heterogêneos de organizar o cuidado à população rural em municípios das regióes Norte e Nordeste de Minas Gerais. A existência de pontos de apoio nas áreas rurais aparece como importante estratégia para ampliar o acesso da população rural a açôes ofertadas na APS, embora, em algumas realidades, sua estrutura e seu funcionamento sejam insuficientes ou inadequados para atender às necessidades. Observa-se um investimento das equipes para estarem nos territórios rurais, por meio de consultas, visitas domiciliares e ampliação de acesso a determinados procedimentos. Entretanto, grupos de saúde são predominantemente realizados na UBS da cidade.

Limitaçóes para deslocamento tornam-se uma importante questão tanto para as equipes chegarem aos territórios rurais quanto para a população rural acessar açóes e serviços de saúde restritos à área urbana. Sobre isso, cabe destacar, por um lado, o uso de critérios clínicos pelas equipes para definir prioridades de atendimento nas áreas rurais e, por outro, o ônus físico e financeiro imputado à população rural para se deslocarem até a cidade e acessar serviços de saúde.

É importante destacar os movimentos inventivos que marcam o trabalho do ACS da zona rural, profissional que representa uma personificação do acesso à saúde para as comunidades rurais e que dinamiza as lógicas de funcionamento do transporte e da UBS para potencializar o atendimento às necessidades da comunidade. $\mathrm{O}$ 
trabalho do ACS em zonas rurais revela quáo mais potente se torna o cuidado à saúde quando o que o orienta são mais as necessidades singulares das pessoas do que as normas instituídas para o seu funcionamento.

A composição dos grupos focais por conveniência pode ser uma limitação deste estudo, na medida em que as especificidades dos territórios do Norte e do Nordeste de Minas Gerais restringem a generalização dos resultados para outras realidades. Entretanto, o estudo contribuiu para aprofundar a compreensão sobre a organização dos serviços da APS para o atendimento às populaçóes rurais, indicando fragilidades e possibilidades para a garantia do direito à saúde a essas populaçôes. ${ }^{1}$

\section{Referências}

ALONSO, C. M. C.; BÉGUIN, P. D.; DUARTE, F. J. C. M. Trabalho dos agentes comunitários de saúde na Estratégia Saúde da Família: metassíntese. Rev. Saúde Pública, v. 52, n. 14, p. 1-13, 2018. ARRUDA, N. M., MAIA, A. G.; ALVES, L. C. Desigualdade no acesso à saúde entre as áreas urbanas e rurais do Brasil: uma decomposição de fatores entre 1998 a 2008. Cad. Saúde Pública, v. 34, n.6, p. 1-14, 2018.

BAPTISTINI, R. A.; FIGUEIREDO, T. A. M. Agente comunitário de saúde: desafios do trabalho na zona rural. Ambiente \& Sociedade, v.17, n. 2, p. 53-70, 2014.

BARDIN, L. Análise de conteúdo. 3a reimpressão. Lisboa: Ediçôes 70, 2016.

BERTUZZI, D.; PASKULIN, L. G. M; MORAIS, E. P. Arranjos e rede de apoio familiar de idosos que vivem em uma área rural. Texto Contexto Enfermagem, v. 21, n.1, p. 158-66, 2012.

BHAT, D. et al. Access to breast cancer treatment and reconstruction in rural populations: do women have a choice? Journal Surgical Reserach, n. 254, p. 223-231, 2020.

BRASIL. Ministério da Saúde. Portaria no 2436, de 21 de setembro de 2017. Aprova a Política Nacional de Atenção Básica, estabelecendo a revisão de diretrizes para a organização da Atenção Básica, no âmbito do Sistema Único de Saúde (SUS). Brasília: Ministério da Saúde, 2017.

. Ministério da Saúde. Portaria no 2.311, de 23 de outubro de 2014. Altera a Portaria no 2.866/GM/MS, de 2 de dezembro de 2011, que institui, no âmbito do Sistema Único de Saúde (SUS), a Politica Nacional de Saúde Integral das Populaçōes do Campo e da Floresta (PNSIPCF). Brasília: Ministério da Saúde, 2014.

COSTA, L. A. et al. Estratégia Saúde da Família rural: uma análise a partir da visão dos movimentos populares do Ceará. Saúde em Debate, v. 43, n. 8, p. 36-49, 2019.

DALL'AGNOL, C.M.; TRENCH, M. H. Grupos focais como estratégia metodológica em pesquisas na Enfermagem. Revista Gaúcha Enfermagem, v. 20, n. 1, p. 5-25, 1999. 
FACCHINI, L. A.; TOMASI, E.; DILÉLIO, A. S. Qualidade da Atenção Primária à Saúde no Brasil: avanços, desafios e perspectivas. Saúde em Debate, v. 42, n. esp 1, p. 208-223, 2018.

GARNELO, L. et al. Acesso e cobertura da Atenção Primária à Saúde para populações rurais e urbanas na região norte do Brasil. Saúde em Debate, v. 42, n 1, p. 81-99, 2018.

INSTITUTO BRASILEIRO DE GEOGRAFIA E ESTATÍSTICA. Censo Demográfico 2010. Rio de janeiro: IBGE; 2011.

LACERDA, T. L. et al. Política Nacional de Atenção Básica 2017: implicações no trabalho do Agente Comunitário de Saúde. Saúde em Debate, v. 44, n. 124, p. 58-69, 2020.

LOPES, M. G. K. et al. Grupos focais: uma estratégia para pesquisa em saúde. $R S B O$, v. 7., n. 2, 2010.

MOROSINI, M. V. G. C.; FONSECA, A. F. Os agentes comunitários de saúde na Atenção Primária à Saúde no Brasil: inventário de conquistas e desafios. Saúde em Debate, v. 42, n. 1, p. 261-274, 2018.

PESSOA, V. M.; ALMEIDA, M. M.; CARNEIRO, F. F. Como garantir o direito à saúde para as populaçóes do campo, da floresta e das águas no Brasil? Saúde em Debate, v. 42, n. especial 1, p. 302-14, 2018.

PINTO, A. G. A. et al. Vínculos subjetivos do agente comunitário de saúde no território da Estratégia Saúde da Família. Trabalho, Educação e Saúde, v. 15, n. 3, p. 789-802, 2017.

SANTOS, M. R.; PIERANTONI, C. R.; SILVA, L. L. Agentes comunitários de saúde: experiências e modelos do Brasil. Physis: Revista de Saúde Coletiva, v. 20, n. 4, p. 1165-1181, 2010. SILVA, E. S. A saúde do campo e o processo de trabalho da equipe de saúde da família. 2017. 128f. Dissertação (Mestrado) - Instituto Aggeu Magalhães, Fundação Oswaldo Cruz, Recife, 2017.

SIPS, I. et al. Community Care Workers, Poor Referral Networks and Consumption of Personal Resources in Rural South Africa. Plos one. v. 9, n. 4, e95324, 2014.

STRALEN, A. C. S. V. et al. Percepção de médicos sobre fatores de atração e fixação em áreas remotas e desassistidas: rotas da escassez. Physis Revista de Saúde Coletiva, v. 27, n. 1, p. 147-172, 2017.

\section{Nota}

${ }^{1}$ A.N. Soares e T.L e Silva realizaram a concepçâo do estudo; o planejamento, a coleta, a análise e a interpretação dos dados; a redação e a aprovação da versão final do artigo; A.A.A.M. Franco e T.F. Maia participaram do planejamento e da coleta de dados; da redação e da aprovaçáo da versão final do artigo. 


\section{Abstract}

\section{Healthcare for rural populations: perspectives and practices of community health agents}

This study aimed to understand how community health agents perceive the organization of Primary Health Care for the health care of rural populations in small municipalities in the state of Minas Gerais, Brazil. Qualitative study carried out in six small cities in the North and Northeast regions of Minas Gerais. Six focus groups were carried out between July and December 2019. Results showed different strategies to expand the access of the rural population to actions offered in Primary Health Care, such as the construction of support points and the organization of teams to offer consultations, home visits and certain procedures in the rural areas themselves. However, the organization of rural population care seems to be guided by clinical criteria and the ability to move teams and users, rather than by the health needs of population. We hope the data on different realities in rural territories can contribute to the development of strategies to expand and consolidate public health policies for the Brazilian rural population.

Keywords: community health workers; Primary Healthcare; rural health. 